\title{
Amorous scorpionflies: causes and consequences of the long pairing prelude of Panorpa cognata
}

\author{
LEIF ENGQVIST \& KLAUS PETER SAUER \\ Institut für Evolutionsbiologie und Ökologie, Rheinische Friedrich-Wilhelms-Universität Bonn \\ (Received 22 January 2001; initial acceptance 20 April 2001; \\ final acceptance 16 October 2001; MS. number: 6810R)
}

\begin{abstract}
The scorpionfly Panorpa cognata has a prolonged premating period. After the male attracts a female, there is usually a long delay, from a few minutes to almost $7 \mathrm{~h}$, before the male initiates copulation by secreting a salivary mass. In our experiments, we manipulated the amount of food, and hence the condition, of males and then measured their premating duration. The premating duration was strongly influenced by male nutrient availability and, consequently, male mating resource limitation. Males with ample resource availability, that is with large salivary glands, initiated copulations faster than males with limited resources. In addition, premating duration decreased with increasing male age. The secretion of a salivary mass was more likely to result in a successful copulation if males delayed copulation. When males initiated copulation soon after attracting a mate, nuptial gift offering often failed because of interruption by other scorpionflies or female rejection. Since the value of each invested salivary mass is high for males with limited resources, we suggest that these males invest prudently: to enhance the probability of a return on their investment, they delay secreting the salivary mass until they are confident that females are motivated to mate. Furthermore, with this strategy, males enhance the likelihood of copulating in a sheltered location, where they are unlikely to be interrupted by intruders. Alternative hypotheses are that males in poor condition have more difficulty in persuading females or that males with small salivary glands need longer to produce the salivary mass.
\end{abstract}

() 2002 The Association for the Study of Animal Behaviour. Published by Elsevier Science Ltd. All rights reserved.

In the majority of animal species males play the active role in courtship behaviour. Since males have considerable reproductive gains from mating (Bateman 1948; Trivers 1972), their motivation to mate is usually high. However, pair formation is not always followed by the male initiating copulation. Instead, in a number of species, male courtship can last for hours, or even days, before copulations begin (see e.g. Schaller 1971; Watson 1991a; Jormalainen 1998; Proctor 1998). Similarly, in a few species, pairs start copulating instantly after pair formation, but sperm transfer is considerably delayed (Svärd \& Wiklund 1988; Watson 1991b; Fänger \& Naumann 1998). Numerous studies have tried to assess the adaptive significance of long premating periods in different animal species. The most common reason seems to be that females are receptive for only a short time (cf. Parker 1970). Males therefore locate and guard an immature female against other males until the female reaches maturity, and copulation takes place. Such behaviour is well known in crustaceans such as amphipods (e.g.

Correspondence: L. Engqvist, Institut für Evolutionsbiologie und Ökologie, Rheinische Friedrich-Wilhelms-Universität Bonn, An der Immenburg 1, D-53121 Bonn, Germany (email: lengqvist@evolution. uni-bonn.de).
Elwood \& Dick 1990) and isopods (e.g. Jormalainen 1998) but also occurs frequently in other animal groups, such as insects and spiders (e.g. Parker 1970; Watson 1991a). A similar phenomenon has been reported for certain butterflies and moths (e.g. Svärd \& Wiklund 1988; Fänger \& Naumann 1998), where males delay sperm transfer to as close to oviposition as possible. Presumably, this behaviour enables males to prevent sperm competition, since females are less likely to remate before oviposition (cf. Svärd \& Wiklund 1988; Alcock 1994).

Here we report long premating periods in the scorpionfly Panorpa cognata Ramb. In this species, males attract females by emitting long-range pheromones as described for other scorpionflies (Thornhill 1979; Byers \& Thornhill 1983). Copulation is not initiated immediately; instead pairs engage in long premating associations. These are characterized by continuous male wing and abdominal movements, interrupted sporadically by brief genital contact (ca. $5 \mathrm{~s}$ ). Finally, the males initiate copulation by producing a salivary mass, which represents a costly mating effort. Males increase copulation duration (Engqvist \& Sauer 2001), and consequently number of sperm transferred (L. Engqvist \& K. P. Sauer, unpublished data), by producing a larger salivary mass before 
copulation. The salivary mass is secreted from the enlarged labial gland, which fills up a major part of the thorax and abdomen. Females feed on the salivary mass during copulation, and terminate copulation when they have consumed it.

The long pairing prelude observed in P. cognata cannot be interpreted as precopulatory mate guarding. Males cannot prevent females deserting or defend them against competitive males. Furthermore, the males' behaviour does not inhibit females from remating before oviposition. Initially, we noted a remarkably high variance in premating duration. Some males initiate matings immediately after attracting a female, whereas others wait for several hours. We were interested in the causes and consequences of this behaviour. We first examined the natural occurrence and variation of premating duration by observing enclosure populations. We then carried out a series of experiments, where we manipulated male condition and female quality and analysed the effect of these factors on premating duration. In the light of our results, we suggest a novel hypothesis that accounts for the observed phenomenon in this species: that males delay initiating copulation to decrease the probability of wasting valuable mating resources.

\section{METHODS}

\section{Observations}

Our observations were made during three consecutive generations: first and second generation 1998 and the first generation 1999. In all generations, we used $F_{1}$ offspring from field-caught adults (near Freiburg i. Br. in southwestern Germany) that were bred using standard breeding protocols (see Sauer 1970, 1977; Thornhill \& Sauer 1992). After emergence, adults were individually marked with a colour spot on one of their forewings and held in two large enclosures $(150 \times 70 \mathrm{~cm}$ area and $70 \mathrm{~cm}$ high) containing cut stinging nettle, Urtica dioica, stems and leaves, which were replaced daily if necessary. The enclosures were made of Perspex and each contained 15 males and 15 females, except during the first generation in 1998 where each enclosure contained 12 males and 12 females. In each generation, the two populations were assigned to one of two feeding regimes. The scorpionflies were supplied with water ad libitum and either five (low food availability) or 10 (high food availability) onesegment pieces of last-instar mealworms, Tenebrio molitor, per enclosure and day. In the first generation in 1998 food availability was set to four (low) and eight (high) one-segment pieces of last-instar mealworms per day. The scorpionflies were held at $18^{\circ} \mathrm{C}$ and an 18:6 h light:dark cycle. Males start 'calling' a few hours before sunset, and matings occur at night and dawn. Each day we started observations $6 \mathrm{~h}$ prior to the onset of the scotophase. At the same time, we released the scorpionflies into the enclosures. We observed the enclosures each day until the end of the nocturnal mating activities, at which time we put each individual into a small $(8 \times 3.5 \mathrm{~cm})$ plastic tube until the next day. The conditions were the same as during the observational phase and the scorpionflies had access to water ad libitum but not to food. Each day we swapped populations between enclosures.

We made observations every day until the end of the mating season (first generation 1998: 44 days; second generation 1998: 47 days; first generation 1999: 42 days). In this and the following experiments, we defined the premating period to begin when females were standing closer than $5 \mathrm{~cm}$ to the male. Males then almost invariably stop 'calling' by reverting the pheromonal gland. We recorded behavioural data of female-male interactions including the time of female attraction and salivary mass secretion, the start of copulation and copulation duration. If interactions did not result in a copulation, or if copulations were interrupted prematurely, we noted the time of female desertion.

\section{Male Condition}

To investigate the influence of male condition on premating duration, we conducted two experiments. In both experiments, we measured the premating duration of each male in two copulations. In this way, we were also able to estimate the repeatability of male premating duration. In the first experiment, we manipulated male condition, by changing nutrient availability, and measured the premating duration of males in two independent copulations. In the second experiment, all males were held on a low-nutrient diet until their first copulation. Thereafter, we randomly assigned males to one of two treatments. The first half were fed ad libitum, the other half were deprived of food. Males were then allowed to copulate once more, and we measured the premating duration again.

\section{Experiment 1}

Sixty males were kept in two large enclosures $(150 \times 70 \mathrm{~cm}$ area and $70 \mathrm{~cm}$ high). Each enclosure was provided with either 10 (good condition) or five (poor condition) segments of last-instar mealworms per day. Every day we removed the scorpionflies and exchanged them between enclosures. Shortly after males had reached sexual maturity (ca. 10 days of age), we conducted mating trials in enclosures of medium size $(30 \times 30 \mathrm{~cm}$ area and $60 \mathrm{~cm}$ high). We used 10 enclosures and each day the males from each treatment were randomly assigned to be placed in one of five randomly selected enclosures. Thus, a maximum of six males and six virgin females picked at random were placed in each enclosure. For each male, we measured the time between attracting a female and producing the salivary mass. After the first successful copulation, each male was supplied with half a segment of a mealworm to recover from the weight lost by secreting the salivary mass. Males were given the opportunity to remate on the following day with another female.

Before every mating trial, we weighed males to the nearest $0.1 \mathrm{mg}$. After the two matings, we measured the mean length of the males' left and right forewings to the nearest $0.1 \mathrm{~mm}$ with a dissecting microscope at $10 \times$ magnification, and used it as a measure of body size. We used the residuals from the regression of body weight on 
body size as an index of condition. Our manipulation resulted in a significant difference in male condition between the two male nutrient treatments (poor condition: $\bar{X} \pm \mathrm{SE}=-2.13 \pm 0.66 \mathrm{mg} ; \mathrm{N}=24$; good condition: $\left.1.97 \pm 0.73 \mathrm{mg} ; N=26 ; F_{1,48}=17.2, P=0.0001\right)$. Twenty-six males from each treatment successfully mated twice. Owing to worn-out wing tips, we could not reliably measure the condition of two males in the poorcondition treatment.

\section{Experiment 2}

This experiment was performed exactly as the previous one except that all males were held on a low-nutrient diet (five segments of last-instar mealworms per enclosure and day) before the first mating. After the first copulation, males were either given three mealworm segments each (fed males, $N=16$ ) or no food (food-deprived males, $N=15)$.

There was no difference in weight at first copulation between males from the two treatments (food-deprived males: $\bar{X} \pm \mathrm{SE}=39.6 \pm 0.58 \mathrm{mg}$; fed males: $39.2 \pm 0.42 \mathrm{mg}$; $t$ test: $\left.t_{30}=0.62, P>0.6\right)$. The food-deprived males weighed significantly less in their second than the first copulation (mean weight increase between copulations: $\bar{X} \pm \mathrm{SE}=-1.04 \pm 0.41 \mathrm{mg}$; paired $t$ test: $\left.t_{14}=2.51, P<0.05\right)$. The fed males weighed significantly more in their second copulation than the first copulation (mean weight increase between copulations: $7.62 \pm 0.96 \mathrm{mg}$; paired $t$ test: $\left.t_{15}=7.92, P<0.0001\right)$.

\section{Salivary Gland and Salivary Mass Size}

We conducted mating trials as in the previous experiment. However, just after salivary mass production but prior to copulation, we interrupted and separated pairs. The males $(N=34)$ were immediately killed under carbon dioxide anaesthesia and transferred to tubes containing $70 \%$ ethanol, where they were held until preparation later the same day. We measured the dry weight of the salivary gland and salivary mass to the nearest $0.01 \mathrm{mg}$. For further details of the dissection and measurements see Engqvist \& Sauer (2001). To estimate the dry weight of the salivary gland before copulation, we added the weight of the salivary mass to that of the dissected salivary gland.

\section{Female Quality}

After adult emergence, 150 males were held in small enclosures $(30 \times 30 \mathrm{~cm}$ area and $60 \mathrm{~cm}$ high) until they reached sexual maturity. Ten enclosures were used, and in each enclosure, 15 males were held on a low-nutrient diet. These males were randomly assigned to mate with either a high- or low-quality female. Female quality was manipulated by nutrient availability, which has a large effect on female fecundity. Females were kept individually in small $(8 \times 3.5 \mathrm{~cm})$ plastic tubes. Females assigned to the high-quality treatment were given a one-segment piece of last-instar mealworms every third day and those in the low-quality treatment one segment every sixth day. Our manipulation resulted in a significant difference in fecundity between female treatments (random subsample: high-quality females: $\bar{X} \pm \mathrm{SE}=56.4 \pm 2.4$ eggs; low-quality females: $\left.8.5 \pm 1.8 ; t_{44}=15.8, P<0.001\right)$. We conducted mating trials as in previous experiments with groups of six males and either six high-quality or six low-quality females. Every day we switched enclosures between female treatments.

We measured the premating duration of males in matings immediately after sexual maturation (ca. 10 days). To control for the effect of salivary gland size on premating duration, we interrupted matings immediately after the males produced the salivary mass. As in the previous experiment, we killed and dissected the males and measured the dry weights of the salivary gland and salivary mass. From the sum of these values, we estimated male salivary gland size before copulation.

\section{Statistical Analysis}

Premating duration conformed to normality after log transformation (Lilliefors: $P>0.2$ ). To report means of premating duration, we transformed the values back to linear scale. As recommended by Sokal \& Rohlf (1995, page 413), the reliability of these estimates is given as the 95\% confidence interval (CI). Statistical analyses were performed with SPSS 9.0 and JMP 3.2.2 (power analysis) software. Before performing the ANOVAs, we applied the Levene test to ascertain homoscedasticity of variances between treatments. For the repeated measures ANOVA, this was done for each measure separately. In addition, we ensured that the variance in the difference between the two measures did not differ between treatments. For the ANCOVA models, we used the Tukey-Kramer method to compare regression coefficients between treatments to make sure that the assumption of homogeneity of slopes was fulfilled. In addition, homoscedasticity of variances was tested twice, first, disregarding the covariate and then comparing the residual variance. The assumptions for an ANCOVA model were not violated at the significance level of $P=0.1$, except for one case (residual variance between generations, see below), in which we analysed the data from the three generations separately. Statistical tests are two tailed unless specified otherwise.

\section{RESULTS}

\section{Observations}

We successfully measured the premating duration of 344 copulations (first generation 1998: $N=74$; second generation 1998: $N=161$; first generation 1999: $N=109$ ). Premating duration was highly variable, ranging from almost immediate copulation initiation to $392 \mathrm{~min}$ (mean in first generation 1998: $140.2 \mathrm{~min}$; 63.7$308.4 \mathrm{~min}$ (range of mean $\pm 1 \mathrm{SD}$ ); second generation 1998: $46.0 \mathrm{~min}$; $16.2-130.2 \mathrm{~min}$; first generation 1999: 71.1 min; $27.9-181.1 \mathrm{~min})$. Since we found significant differences in residual variance in premating duration between generations (Levene test: $F_{2,341}=6.92, P<0.001$ ), we analysed the data from the three generations separately. We then used Fisher's method of combining these 
Table 1. Analysis of premating duration in the enclosure populations

\begin{tabular}{|c|c|c|c|c|}
\hline Source of variation & $d f$ & $\begin{array}{l}\text { Mean sum } \\
\text { of squares }\end{array}$ & $F$ & $P$ \\
\hline \multicolumn{5}{|l|}{ First generation 1998} \\
\hline Male age & 1 & 1.44 & 15.1 & $<0.001$ \\
\hline Male treatment & 1 & 0.41 & 4.3 & 0.041 \\
\hline Model & 2 & 0.91 & 9.5 & $<0.001$ \\
\hline Error & 71 & 0.09 & & \\
\hline \multicolumn{5}{|c|}{ Second generation 1998} \\
\hline Male age & 1 & 4.29 & 24.2 & $<0.0001$ \\
\hline Male treatment & 1 & 0.76 & 4.2 & 0.040 \\
\hline Model & 2 & 2.35 & 13.2 & $<0.0001$ \\
\hline Error & 158 & 0.18 & & \\
\hline \multicolumn{5}{|c|}{ First generation 1999} \\
\hline Male age & 1 & 0.17 & 1.3 & $>0.2$ \\
\hline Male treatment & 1 & 4.38 & 34.7 & $<0.0001$ \\
\hline Model & 2 & 2.20 & 17.4 & $<0.0001$ \\
\hline Error & 106 & 0.13 & & \\
\hline \multicolumn{5}{|c|}{ Overall test of significance } \\
\hline Male age & 6 & $45.8^{n}$ & & $<0.0001$ \\
\hline Male treatment & 6 & 46.6 & & $<0.0001$ \\
\hline
\end{tabular}

Each generation was analysed separately, and subsequently a nonparamertric, overall test of significance was performed.

probabilities to create an overall test of significance (Sokal \& Rohlf 1995, page 794). Overall, male food availability and age had significant effects on the premating duration. Courtship was significantly longer in the treatment with low food availability (Table 1, Fig. 1), and it decreased with increasing male age (Table 1, Fig. 1).

To analyse whether the premating duration was associated with the resulting copulation duration, we used the residual premating duration from the previous analysis as the independent and copulation duration as the dependent variable. Except for a weak significant negative correlation in the second generation 1998, premating duration did not correlate with copulation duration (first generation 1998: $r=0.089, F_{1,67}=0.53, P>0.4$; second generation 1998: $r=-0.175, F_{1,126}=3.96, P=0.05$; first generation 1999: $\left.r=0.04, F_{1,90}=0.15, P>0.7\right)$. The overall test also revealed no significant association between copulation duration and premating duration. $\left(\chi_{6}^{2}=3.78\right.$, $P>0.5$ ). In all these analyses 55 observations with missing copulation duration had to be omitted.

To ensure that the observed effect of male age was not a side-effect of the use of pseudoreplicated data, we performed a stepwise analysis of variance. We first calculated the Studentized residual premating duration of all copulations taking male individual into account (i.e. mean premating duration equals zero for all males, and the SDs all equal one). When controlling for male individual, male age still had a significant effect on the premating duration in two of the three generations (first generation 1998: $r=-0.373, F_{1,70}=11.3, P<0.001$; second generation 1998: $r=-0.478, \quad F_{1,159}=47.0, \quad P<0.0001$; first generation 1999: $\left.r=-0.147, F_{1,104}=2.30, P>0.1\right)$, as well as in the overall test $\left(\chi_{6}^{2}=62.8, P<0.0001\right)$.
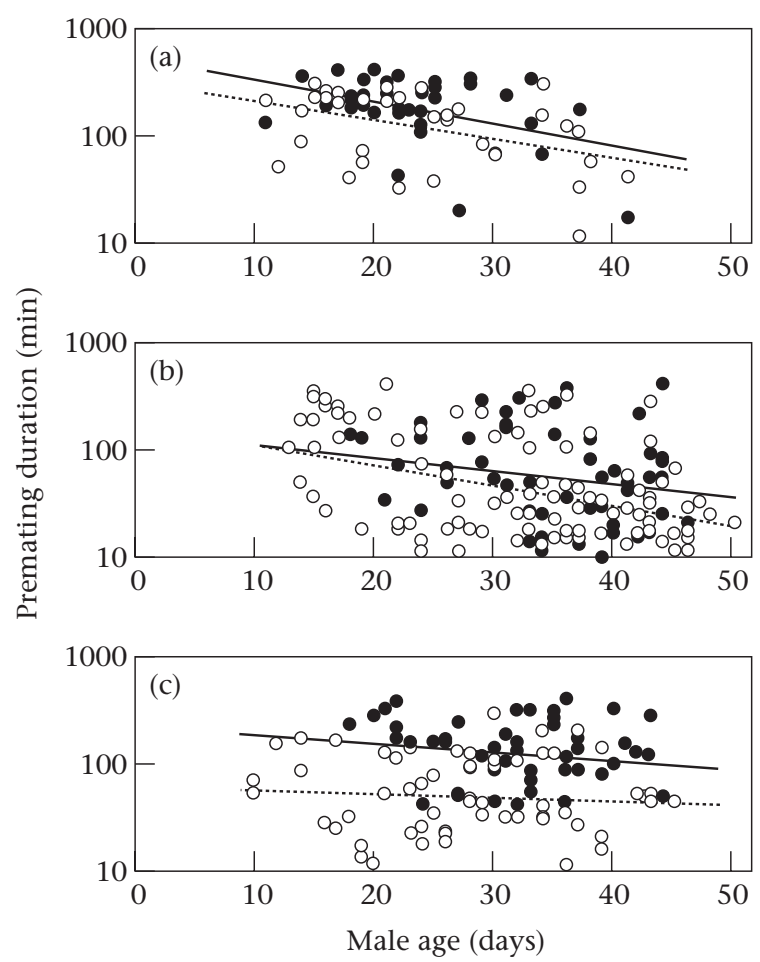

Figure 1. Influence of male age and food availability on premating duration in independent enclosure populations. (a) First generation 1998, (b) second generation 1998, (c) first generation 1999. The lines are from least-square regressions $(\bullet, \ldots$ : low food availability; $0, \cdots \cdot$ : high food availability). Note the logarithmic scale of the $Y$ axis.

In some cases salivary mass production did not result in successful copulations. Instead, females left without consuming the salivary mass, before or just after the onset of copulation. Alternatively, pairs were disturbed and interrupted by other individuals (usually males) just before or in the early phase of copulation. In the two generations (second generation 1998, first generation 1999) where we recorded female desertion or interruptions, the probability of successful copulations increased with increasing premating duration (logistic regression: second generation 1998: $N=161, B=-2.65 \pm 0.62$, $\chi_{2}^{2}=26.8, \quad P<0.0001$; first generation 1999: $N=109$, $B=-1.47 \pm 0.72, \chi_{2}^{2}=4.36, P<0.05$; Fig. 2 ).

The attraction of a female rarely resulted in the production of a salivary mass and copulation. Instead, in the majority of cases, females left at an early stage of courtship $(N=1034$; median $10 \mathrm{~min}$; first and third quartile interval 4-23 min; Fig. 3).

\section{Male Condition}

\section{Experiment 1}

Treatment had a significant effect on the premating duration. Males in the poor-condition treatment had significantly longer premating periods than males in the good-condition treatment (mean of both copulations and 95\% CI: poor condition: 66.0, 47.4-91.7 min; good condition: $\left.24.7,18.4-33.3 \mathrm{~min} ; t_{50}=4.33, P<0.001\right)$. The 


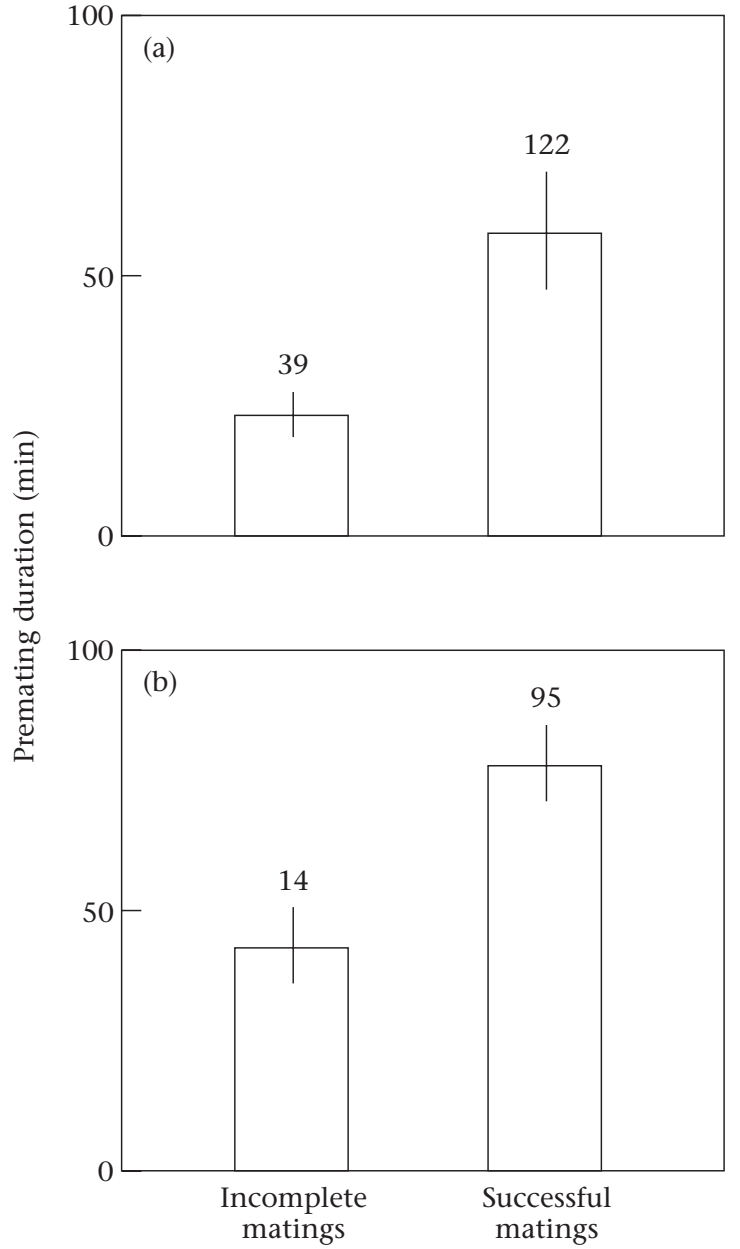

Figure 2. Mean $\pm 95 \%$ confidence intervals for premating duration of successful matings compared to matings in which male mating resources were only incompletely exploited by females. (a) Second generation 1998, (b) first generation 1999. Sample sizes are given above the bars.

premating duration of males was significantly repeatable in consecutive matings (repeated measures ANOVA, coefficient of intraclass variation: $r_{\mathrm{i}}=0.370, F_{51,51}=2.17$, $P<0.01$ ), indicative of consistent male behaviour. There also appeared to be an effect, although not reaching significance, of mating number on premating duration (repeated measures ANOVA: $F_{1,51}=3.87, P=0.055$ ), which was longer in the first mating (first mating: 48.1, 36.4$63.7 \mathrm{~min}$; second mating: 33.9, 24.2-47.6 min).

One may argue that when testing the effect of male treatment in this experiment and for the observations from the enclosure populations, the number of replicates is inflated, since all individuals receiving a certain treatment were kept in one population. Therefore, we performed an additional analysis using the mean of each population as an observation ( $N=8$ cages, two cages each from the three generations and experiment 1 ). This analysis shows that male treatment had a significant effect on the duration of the premating period (paired $t$ test: $\left.t_{3}=3.2, P<0.05\right)$.

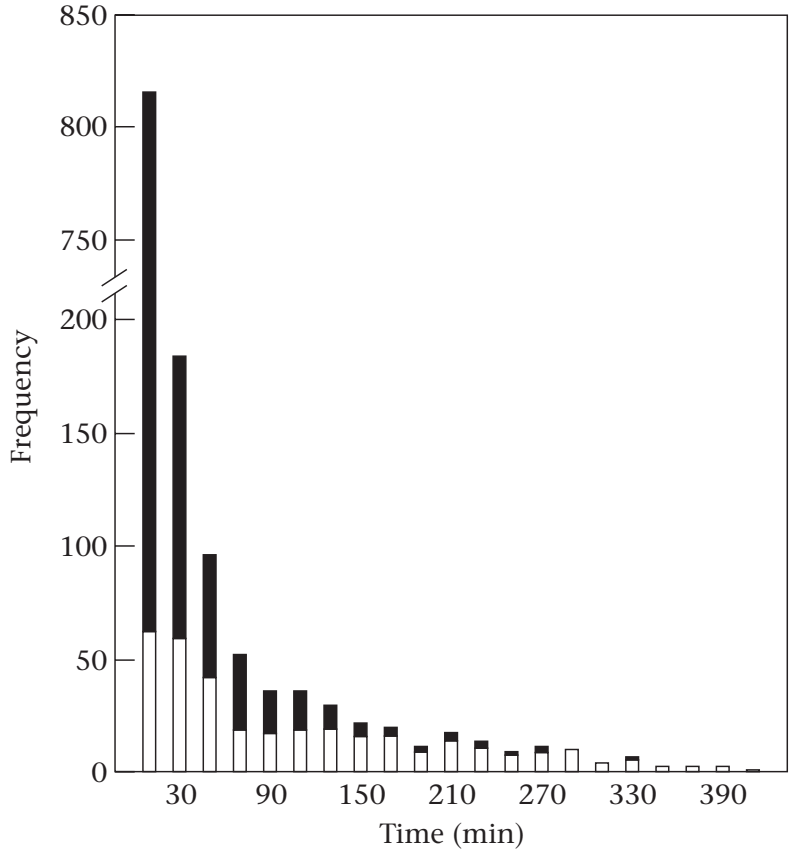

Figure 3. Frequency of female desertion $(\square)$ and male initiation of copulation $(\square)$ in relation to the time since the male attracted the female.

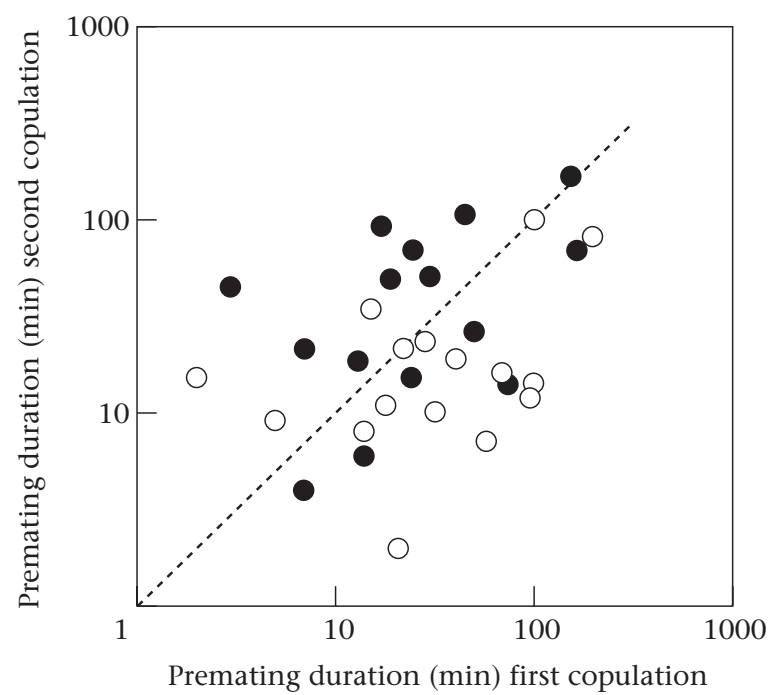

Figure 4. Premating duration in the males' first and second mating in experiment 2. Each data point represents one male that mated twice. •: Food-deprived males; ○: males that were fed ad libitum between copulations. The dashed line indicates expected values assuming no difference between copulations. Note the logarithmic scale of both axes.

\section{Experiment 2}

Males waited significantly longer before they produced the salivary mass in the second copulation if they were previously food deprived than if they were fed (repeated measures ANOVA, copulation number $\times$ treatment interaction: $F_{1,29}=5.36, P<0.05$; Fig. 4$)$. A post hoc test confirmed that fed males produced the salivary mass faster in the second copulation (mean of first copulation and 


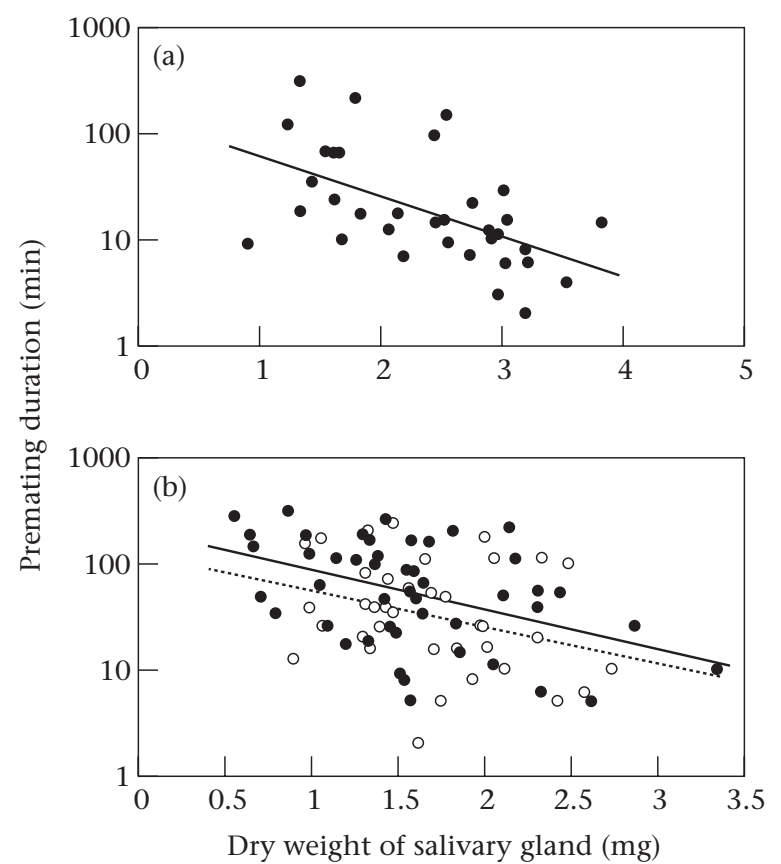

Figure 5. (a) Influence of salivary gland size on premating duration. The line is from the least-square regression $(r=-0.551)$. (b) Influence of salivary gland size and female quality on premating duration. The lines are from least-square regressions. $\bullet, \ldots$ : Matings with highquality females; $0, \cdots$ : matings with low-quality females. Note the logarithmic scale of the $Y$ axis.

95\% CI: 30.3, 16.9-54.2 min; second copulation: 14.9, 9.33-23.8 min; repeated measures ANOVA: $F_{1,15}=5.57$, $P<0.05)$, and food-deprived males waited equally long in the two copulations (first copulation: 24.5, 13.9$43.2 \mathrm{~min}$; second copulation: $32.0 \mathrm{~min}, 18.7-54.7 \mathrm{~min}$; repeated measures ANOVA: $F_{1,14}=0.825, P>0.3$; Fig. 4). The repeatability of the premating duration was significant and of similar magnitude to that in experiment 1 (repeated measures ANOVA: $r_{\mathrm{i}}=0.413, F_{29,29}=2.41$, $P<0.01)$.

\section{Salivary Gland and Salivary Mass Size}

The size of the salivary mass was not correlated with the premating duration (regression coefficient: $-0.593 \pm$ $\left.0.489 ; F_{1,32}=1.47, P>0.2\right)$. Premating duration decreased significantly with increasing male condition and salivary gland size (regression coefficients: male condition: $-0.036 \pm 0.018 ; F_{1,32}=4.00, P<0.05$, one-tailed test of significance, since the effect was predicted on the bases of the previous experiments; salivary gland size: $-0.384 \pm 0.103 ; F_{1,32}=14.0, P=0.001$; Fig. 5a).

A stepwise multiple regression revealed that once the effect of salivary gland size was taken into account (Fig. $5 a)$, no further variable significantly explained any further residual variance (male condition: $F_{1,31}=2.46, P>0.1$; salivary mass size: $\left.F_{1,31}=0.69, P>0.4\right)$. Since the sizes of the salivary gland and salivary mass are highly intercorrelated (see also Engqvist \& Sauer 2001), any correlation between salivary mass size and premating duration may be concealed by the effect of salivary gland size. We therefore controlled for the effect of salivary gland size on the salivary mass size and premating duration by calculating the residuals. However, we found no significant correlation between residual salivary mass size and residual premating duration $\left(r_{32}=0.15, P>0.4\right)$. Thus, unexpectedly long premating durations, with respect to the size of the salivary gland, seem not to be associated with unexpectedly large salivary masses.

\section{Female Quality}

We measured the premating duration of 87 males. Forty-eight males mated with a high-quality female and 39 with a low-quality female. The two groups of males that were assigned to mate with different females did not differ with respect to the size of the salivary gland (highquality females: $\bar{X} \pm \mathrm{SE}=1.72 \pm 0.085 \mathrm{mg} ;$ low-quality females: $\left.1.56 \pm 0.078 \mathrm{mg} ; t_{85}=1.38, P=0.17\right)$. As in the previous experiment, salivary gland size had a significant effect on premating duration and, when we controlled for this effect, the premating duration was somewhat longer in matings with high-quality females (Fig. 5b). However, this difference was not statistically significant (ANCOVA, covariate salivary gland size: $F_{1,84}=16.3, P<0.001$; female quality: $\left.F_{1,84}=2.85, P=0.095\right)$. A power analysis showed that our test had a power of 0.95 to reveal a difference $(\alpha=0.05)$ of 0.180 in $\log$ premating duration between female treatments. At the mean salivary gland size of our sample of $1.64 \mathrm{mg}$, this represents a change in premating duration of 17 min between female treatments (highquality females: $49.5 \mathrm{~min}$; low-quality females: $32.7 \mathrm{~min}$ ).

\section{DISCUSSION}

Some copulations were initiated immediately after the male attracted a female, whereas others were delayed for almost 400 min (Fig. 1). In consecutive matings the premating periods of individual males were similar and repeatable. This difference in premating duration between males was to a large extent explained by differences in male condition (Figs 1, 4). Males in good condition initiated copulations faster, primarily because such males develop larger salivary glands (see also Engqvist \& Sauer 2001), and males with large salivary glands initiated copulation sooner than males with small salivary glands (Fig. 5). Furthermore, premating duration decreased as males aged (Fig. 1). However, since we did not control for salivary gland size in this experiment, older males might have developed larger salivary glands, and this might have generated the effect of age on premating duration.

Why should males with small salivary glands wait longer before they offer females their salivary mass? We suggest that males deliberately delay initiating a copulation, that is by offering a salivary mass, to increase the probability of a successful return for their investment. Since the nuptial gift is more likely to be accepted if premating duration is long (Fig. 2), males with limited resources for salivary mass production should be reluctant to initiate mating immediately. 
The pairing prelude described here for P. cognata is absent in closely related scorpionfly species. If one compares the position of $P$. cognata within the hypothetical phylogenetic tree of the genus Panorpa (cf. Misof et al. 2000), the appearance of this long premating period seems to coincide with two additional apomorphic traits in the mating behaviour of P. cognata: the reduction of the notal organ (cf. Bockwinkel 1990), a clamp-like structure by which the males retain hold of one of the female's forewings during copulation (Byers \& Thornhill 1983; Thornhill \& Sauer 1991), and the offering of only one large salivary mass. In closely related species, the notal organ permits males to retain control of females after they have consumed the salivary mass. Thus, they have time to produce another salivary mass before copulation is interrupted. Consequently, the notal organ enables males to divide their mating effort into many small salivary masses. Panorpa cognata males, in contrast, have to produce one large salivary mass initially to prolong copulation duration and transfer many sperm (Engqvist \& Sauer 2001; L. Engqvist \& K. P. Sauer, unpublished data). Furthermore, in species with a functional notal organ, copulation initiation failed more often when males had experimentally manipulated nonfunctional notal organs (Gerhards 1999; Aumann 2000), presumably because of the loss of male control during this crucial stage of courtship. Thus, although the evolutionary cause of the reduction of the notal organ in P. cognata is unknown, it has apparently led to hazardous copulation initiations. Despite the reduced control of copulation initiation, a larger salivary mass has to be invested initially.

We observed two different reasons for unsuccessful copulation initiations. First, gift delivery sometimes failed. Males glue the secreted salivary mass on to the substrate (usually a leaf) and must then guide the females to find it. If females are reluctant to cooperate, the mating attempt fails, since, owing to the absence of the notal organ, males cannot persuade females to accept gifts. By waiting a long time before initiating copulation, males may test the female's willingness to mate, and increase the probability that the female will cooperate. Second, copulations were often interrupted by other individuals, usually males intending to court the female. If the risk of interruption is not the same everywhere, and males do not know beforehand where it is safe, males that delay salivary mass production may be more certain to have found a sheltered copulation location that is safe from intruders.

However, if males wait a long time, the courtship is more likely to be interrupted and the female will abandon the male (Fig. 3). The majority of females do not remain for long and these females represent missed opportunities for males that hesitate too long. However, we believe it is more important to males not to waste valuable saliva. Males in good condition, with ample mating resources, may afford the risk of wasting a salivary mass and therefore take every opportunity to mate. Males with a limited supply of saliva have only enough resources for a few copulations at the most, and it may therefore be more important that these resources are securely invested than that every possible mating opportunity is seized. Similarly, as males get older it may be advantageous to take more risks, since the probability of future mating opportunities is continuously declining. However, since we did not control for salivary gland size in this experiment, the influence of male age on premating duration may equally well originate from an effect of male age on salivary gland size.

In addition to our hypothesis of male avoidance of wasting resources, the majority of our results are also consistent with two alternative hypotheses: (1) males in poor condition may need longer to persuade females to mate, and (2) males with smaller salivary glands may need longer to produce the salivary mass. The male persuasion hypothesis would also fit well with the result that the premating period was longer, albeit nonsignificantly, in matings with high-quality females (Fig. 5b). In the context of male persuasion, these results would imply that high-quality females are choosier and males need longer to persuade them than low-quality females. Some results, however, do not support the possibility that long premating duration is an attempt to persuade females to mate. Male copulation initiation did not seem to reflect female acceptance, since females occasionally deserted males that had produced a salivary mass (Fig. 2), leading to the irrational conclusion that males that promptly 'persuaded' females were more likely to be rejected.

Males with smaller salivary glands may also need longer to produce the salivary mass and therefore have longer premating durations. None of our observations really contradicts this possibility. However, if this were the main reason for these long premating associations, one would also expect to find a stronger correlation between premating duration and salivary mass size, since it should take longer to produce larger salivary masses, that is, if salivary gland size were held constant, one would expect to find a correlation between premating duration and salivary mass size. The experiment where we investigated the influence of male condition, salivary gland size and salivary mass size on premating duration did not reveal such a correlation. Furthermore, in the enclosure populations, there was no correlation between residual premating duration and copulation duration, which is an index of salivary mass size (Engqvist \& Sauer 2001).

Although we cannot refute these alternative hypotheses, the hypothesis of male avoidance of wasting resources seems, at least at present, to describe best the causes of the observed long premating period in $P$. cognata. To provide a rigid test, however, one must manipulate premating duration, without changing male condition. Our hypothesis would be supported if experimentally prolonged premating periods less often lead to copulation initiations, but that these initiations more often succeed. Correspondingly, copulation initiations following shortened premating periods should more often fail.

Our hypothesis predicts long premating periods whenever relative male mating investment is high, and males cannot control the successful return of their investment. These predictions coincide with intra- and interspecific comparisons. Occasionally male P. cognata court females 
with other food gifts, primarily dead arthropods (see also Thornhill 1981; Sauer et al. 1998). These matings invariably begin immediately after pair formation, irrespective of male condition, which contradicts the hypothesis that males in poor condition need a long time to persuade females to mate, but is in accordance with our hypothesis of male avoidance of wasting resources. Offering prey does not involve a risk of wasting resources to males, since if the female refuses it, males can still use the prey as food. Similarly, other scorpionflies, for example P.germanica, P.vulgaris and P.communis (Sauer et al. 1998; Gerhards 1999; Aumann 2000) readily offer the female a salivary mass shortly after pair formation. As males of these species are able to divide their investment into small salivary masses, which they offer continuously during mating, each salivary mass represents only a small investment. Consequently, there is only a small cost if females refuse the gift.

An interesting aspect of the pairing prelude of $P$. cognata concerns the function of the premating activities, that is the abdominal movements and genital contact. The interpretation of the role of these activities depends on which hypothesis is favoured. If males secure their mating investment or need time to produce the salivary mass, the interpretation would be that males hold the females' attention to make them wait. In contrast, the premating activities may be crucial for males to persuade females to mate. Males may also assess female mating status or fecundity during the courtship period (see e.g. Suter 1990; Lewis \& Iannini 1995). Obvious discrimination against mated females has not been observed, but female fecundity is known to have a significant effect on male mating investment in the salivary mass (see also Engqvist \& Sauer 2001). Engqvist \& Sauer (2001) showed that female quality affected the investment only of males in poor condition in concordance with the present study, which shows that predominantly males in poor condition have long premating periods.

The long premating period of $P$. cognata appears to be similar to the courtship behaviour described for several species of soil arthropods with indirect sperm transfer (Schaller 1971; Proctor 1998), for instance the long 'promenade à deux' of scorpions, the complex pairing dances of many pseudoscorpions and whipscorpions, and the pairing preludes of several centipedes, springtails and silverfish. In these species, pairs also engage in conspicuous long-lasting courtship activities and, finally, males deposit a spermatophore, from which females take up sperm. It does not seem implausible that, like $P$. cognata, these long and occasionally very complex courtship dances have evolved to ensure that a deposited spermatophore, which may be costly for males to produce (Proctor 1998), is not a wasted investment.

\section{Acknowledgments}

We thank Bernhard Misof and Klaus Reinhold, whose valuable comments greatly improved the manuscript, and Elisabeth Platten for helpful support in the laboratory. This work was supported by the Deutsche Forschungsgemeinschaft [Sa 259/5-3].

\section{References}

Alcock, J. 1994. Postinsemination associations between males and females in insects: the mate-guarding hypothesis. Annual Review of Entomology, 39, 1-21.

Aumann, N. 2000. Lebenslaufgeschichte und Paarungssystem der Skorpionsfliege Panorpa communis L. (Mecoptera, Insecta). Ph.D. thesis, University of Bonn.

Bateman, A. J. 1948. Intra-sexual selection in Drosophila. Heredity, 2, 349-368.

Bockwinkel, G. 1990. Stabilisierung der zeitlichen und räumlichen Nutzungsmuster von Panorpa communis und P. vulgaris. Ph.D. thesis, University of Bielefeld.

Byers, G. W. \& Thornhill, R. 1983. Biology of the Mecoptera. Annual Review of Entomology, 28, 203-228.

Elwood, R. W. \& Dick, J. T. A. 1990. The amorous Gammarus: the relationship between precopula duration and size-assortative mating in G. pulex. Animal Behaviour, 39, 828-833.

Engqvist, L. \& Sauer, K. P. 2001. Strategic male mating effort and cryptic male choice in a scorpionfly. Proceedings of the Royal Society of London, Series B, 268, 729-735.

Fänger, H. \& Naumann, C. M. 1998. Genital morphology and copulatory mechanism in Zygaena trifolii (Esper, 1783) (Insecta, Lepidoptera, Zygaenidae). Acta Zoologica, 79, 9-24.

Gerhards, U. 1999. Paarungssystem und Spermienkonkurrenzmechanismus der Skorpionsfliege Panorpa germanica (Insecta, Mecoptera). Ph.D. thesis, University of Bonn.

Jormalainen, V. 1998. Precopulatory mate guarding in crustaceans: male competitive strategy and intersexual conflict. Quarterly Review of Biology, 73, 275-304.

Lewis, S. M. \& Iannini, J. 1995. Fitness consequences of differences in male mating behaviour in relation to female reproductive status in flour beetles. Animal Behaviour, 50, 1157-1160.

Misof, B., Erpenbeck, D. \& Sauer, K. P. 2000. Mitochondrial gene fragments suggest paraphyly of the genus Panorpa (Mecoptera, Panorpidae). Molecular Phylogenetics and Evolution, 17, 76-84.

Parker, G. A. 1970. Sperm competition and its evolutionary consequences in the insects. Biological Reviews, 45, 525-567.

Proctor, H. C. 1998. Indirect sperm transfer in arthropods: behavioral and evolutionary trends. Annual Review of Entomology, 43, 153-174.

Sauer, K. P. 1970. Zur Monotopbindung einheimischer Arten der Gattung Panorpa (Mecoptera) nach Untersuchungen im Freiland und im Laboratorium. Zoologische Jahrbücher: Abteilung für Systematik, Ökologie und Geographie der Tiere, 97, 201-284.

Sauer, K. P. 1977. The adaptive significance of genetic variability of photoperiodic response in Panorpa vulgaris. Zoologische Jahrbücher: Abteilung für Systematik, Ökologie und Geographie der Tiere, 104, 489-538.

Sauer, K. P., Lubjuhn, T., Sindern, J., Kullmann, H., Kurtz, J., Epplen, C. \& Epplen, J. T. 1998. Mating system and sexual selection in the scorpionfly Panorpa vulgaris (Mecoptera: Panorpidae). Naturwissenschaften, 85, 219-228.

Schaller, F. 1971. Indirect sperm transfer by soil arthropods. Annual Review of Entomology, 16, 407-446.

Sokal, R. R. \& Rohlf, F. J. 1995. Biometry. 3rd edn. New York: W. H. Freeman.

Suter, R. B. 1990. Courtship and the assessment of virginity by male bowl and doily spiders. Animal Behaviour, 39, 307-313.

Svärd, L. \& Wiklund, C. 1988. Prolonged mating in the monarch butterfly Danaus plexippus and nightfall as a cue for sperm transfer. Oikos, 52, 351-354.

Thornhill, R. 1979. Male pair-formation pheromones in Panorpa scorpionflies (Mecoptera: Panorpidae). Environmental Entomology, 8, 886-888. 
Thornhill, R. 1981. Panorpa (Mecoptera: Panorpidae) scorpionflies: systems for understanding resource-defense polygyny and alternative male reproductive efforts. Annual Review of Ecology and Systematics, 12, 355-386.

Thornhill, R. \& Sauer, K. P. 1991. The notal organ of the scorpionfly (Panorpa vulgaris): an adaptation to coerce mating duration. Behavioral Ecology, 2, 156-164.

Thornhill, R. \& Sauer, K. P. 1992. Genetic sire effects on the fighting ability of sons and daughters and mating success of sons in a scorpionfly. Animal Behaviour, 43, 255-264.
Trivers, R. L. 1972. Parental investment and sexual selection. In: Sexual Selection and the Descent of Man (Ed. by B. Campbell), pp. 163-179. Chicago: Aldine.

Watson, P. J. 1991a. Multiple paternity and first mate sperm precedence in the sierra dome spider Linyphia litigosa (Linyphiidae). Animal Behaviour, 41, 135-148.

Watson, P. J. 1991b. Multiple paternity as genetic bet-hedging in female sierra dome spiders, Linyphia litigosa (Linyphiidae). Animal Behaviour, 41, 343-360. 